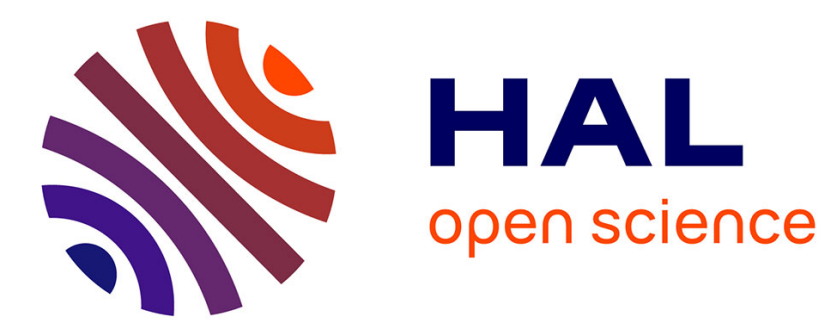

\title{
Characterization of open woodwind toneholes by the tube reversed method
}

Hector Garcia Mayen, Jean Kergomard, Christophe Vergez, Philippe

Guillemain, Michael Jousserand, Marc Pachebat, Patrick Sanchez

\section{- To cite this version:}

Hector Garcia Mayen, Jean Kergomard, Christophe Vergez, Philippe Guillemain, Michael Jousserand, et al.. Characterization of open woodwind toneholes by the tube reversed method. 2021. hal03230052

\section{HAL Id: hal-03230052 \\ https://hal.science/hal-03230052}

Preprint submitted on 19 May 2021

HAL is a multi-disciplinary open access archive for the deposit and dissemination of scientific research documents, whether they are published or not. The documents may come from teaching and research institutions in France or abroad, or from public or private research centers.
L'archive ouverte pluridisciplinaire HAL, est destinée au dépôt et à la diffusion de documents scientifiques de niveau recherche, publiés ou non, émanant des établissements d'enseignement et de recherche français ou étrangers, des laboratoires publics ou privés. 


\section{Characterization of open woodwind toneholes by the tube reversed method}

H. Garcia Mayén, ${ }^{1}$ J. Kergomard, ${ }^{2, a}$ C. Vergez, ${ }^{2}$ P. Guillemain, ${ }^{2}$ M. Jousserand, ${ }^{1}$ M.

Pachebat, ${ }^{2}$ and P. Sanchez ${ }^{2}$

${ }^{1}$ Buffet Crampon, 5 rue Maurice Berteaux1, Mantes-la-Ville, 78711,

France

${ }^{2}$ Aix Marseille Univ., CNRS, Centrale Marseille, LMA UMR 7031, Marseille, France

(Dated: 30 April 2021) 
Woodwind tonehole's linear behavior is characterized by two complex quantities: the series and shunt acoustic impedances. A method to determine experimentally these two quantities is presented. It is based on two input impedance measurements. The method can be applied to clarinet-like instruments. The robustness of the method proposed is explored numerically through the simulation of the experiment when considering geometrical and measurement uncertainties. Experimental results confirm the relevance of the method proposed to estimate the shunt impedance. Even the effect of small changes in the hole's geometry, such as those induced by undercutting, are characterized experimentally. The main effect of undercutting is shown to be a decrease of the tonehole's acoustic mass, in agreement with theoretical considerations based on the shape of the tonehole. Experimental results also reveal that losses in toneholes are significantly higher than those predicted by the theory. Therefore the method is suitable for the experimental determination of the shunt impedance, but it is not convenient for the characterization of the series impedance.

\footnotetext{
akergomard@lma.cnrs-mrs.fr
} 


\section{INTRODUCTION}

For woodwind instruments, the effect of toneholes on the intonation and the ease of playing is essential. The present paper focuses on linear behaviour of toneholes, which is especially important for the playing frequencies. The characterization of holes can be independent of the geometry of the resonator (either cylindrical or conical ${ }^{1}$ ). The first theory was given by Keefe $^{2}$, and completed later ${ }^{3,4}$. It is based on matching plane waves within the resonator and the tonehole. The tonehole is characterized by a transfer matrix or an impedance matrix of order 2. Because of reciprocity, only three elements of the matrix are necessary. In the present paper, the tonehole is assumed to be symmetrical, and two elements (i.e., two complex impedances) are sufficient ${ }^{3}$ for asymmetrical toneholes). The theory, based upon modal expansion, assumes the tonehole to be cylindrical, and this leads to a difficulty of the geometric matching between two cylinders. However, the number and nature of the matrix elements does not depend on the shape of the toneholes, and they can be determined either by experiment or numerical discretization ${ }^{5-7}$. The Finite Element Method can be used, but the modeling of boundary layers ${ }^{6}$ and nonlinear behaviour is not straightforward. Acoustic experiment can be also used for the computation of the input impedance of an instrument by using the transfer matrix method: the measurement of the two acoustic impedances make unnecessary the knowledge of the precise geometry. For the computation of the input impedance of an instrument, the acoustic characterization of the toneholes is sufficient. 
Considering the impedance matrix of the tonehole, the elements are essentially acoustic masses. One is in series, modifying the acoustic pressure, and the other is in parallel, modifying the acoustic flow rate. They can be regarded as length corrections to the main tube and to the tonehole, respectively. Nevertheless, for high (i.e., long) toneholes, compressibility (and propagation) effects can appear. Moreover, for both the impedances in series and in parallel, losses (i.e., resistances) exist. Losses added to the series mass are generally ignored, and no theoretical determination exists, while experimental evidence was found by Dalmont ${ }^{7}$ in a nonlinear regime. At low frequencies, the two masses are almost independent of frequency, but they increase when approaching the first cutoff of the main tube ${ }^{3}$ for the $2 \mathrm{D}$, rectangular case). Other shunt acoustic masses intervene, in particular that of the plane mode in the hole, and a resonance of the total shunt mass can occur at high frequency: this is detailed in Section II.

Previous articles $^{7-9}$ took advantage of the tonehole symmetry to limit the experiment to simultaneous measurement of two quantities, the input impedance of a tube with one tonehole at its middle, and a transfer impedance. This allows avoiding dismantling the apparatus during the measurement. The present paper aims at exploring another method. It limits the measurement to two input impedances, by turning the cylindrical tube, the extremity being open. Thus the termination impedance is unchanged when turning the tube. The drawback is the need of dismantling the set up.

In Sect. II, the direct calculation is performed by using the theoretical, known model of a cylindrical tonehole on a cylindrical tube. In Sect. III, the inverse problem is computed, and a simulation of experiment is done, assuming wrong values of some parameters, such as 
the main tube length, the location of the tonehole and the accuracy of the input impedance measurement. This allows choosing appropriate geometric parameters of the main tube, in order to achieve results with high accuracy. Sect. IV describes the experimental method and results for cylindrical toneholes, with similar dimensions to those of oaclarinet. Sect. V presents the results for examples of undercut toneholes. Sect. VI discusses the validity and interest of the method.

\section{MODEL OF A TUBE WITH AN OPEN TONEHOLE}

The radii of the main tube and the hole are denoted $a$ and $b$, respectively. The wavenumber in free space is denoted $k=\omega / c ; \omega$ is the angular frequency, and $c$ is the sound speed in free space. The wavenumber involving viscous-thermal losses in the main tube is given by a standard expression ${ }^{10}$ :

$$
k_{a}=k\left[1+1.044 \sqrt{-2 j} / r_{v}-1.08 j / r_{v}^{2}\right]
$$

where $r_{v}=a \sqrt{\omega \rho / \mu}$ for the main tube. $\rho$ is the air density, and $\mu$ the air viscosity. The same formula holds for the tonehole, with the notations $k_{b}$ and $b$. The characteristic impedances are $Z_{c}=\rho c / \pi a^{2}$ and $Z_{c h}=\rho c / \pi b^{2}$. The quantities at the left (resp. right) of the tonehole are denoted with subscript 1 (resp. 2). The lengths of the main tube on the two sides of the tonehole are $L_{1}$ and $L_{2}$. The height of the tonehole is $t$. The schematic of the tonehole geometry and the acoustic variables are shown in Fig. 1. In both the main tube and the tonehole, only the plane mode propagates, i.e., higher order modes are evanescent, i.e., the frequency is low enough. The plane mode can be matched on the two sides of the tonehole 
76

77 by the following equation:

78

79 can be written as ${ }^{3}$ : Fig. 2. It is written as follows:

$$
\left(\begin{array}{c}
P_{1} \\
U_{1}
\end{array}\right)=M_{h}\left(\begin{array}{c}
P_{2} \\
U_{2}
\end{array}\right)
$$

where acoustic pressure and volume velocity are denoted $P$ and $U$, respectively. $M_{h}$ is a symmetrical matrix with unity determinant ${ }^{11}$. It corresponds to the T-circuit ${ }^{3,10}$ shown in

$$
M_{h}=\frac{1}{1-Y_{s} Z_{a} / 4}\left(\begin{array}{cc}
1+Y_{s} Z_{a} / 4 & Z_{a} \\
Y_{s} & 1+Y_{s} Z_{a} / 4
\end{array}\right)
$$

The series impedance $Z_{a}$ and the shunt impedance $Z_{s}=1 / Y_{s}$ are the impedances corresponding to the anti-symmetric and symmetric parts of the velocity at the input of the tonehole $^{2,10}$, respectively. For an open tonehole, they are given by the following equations ${ }^{3}$ :

$$
\begin{gathered}
Z_{a}=j k Z_{c} t_{a} \\
Z_{s}=j Z_{c h}\left(k t_{i}+\tan \left[k_{b} t+k\left(t_{m}+t_{r}\right)\right]\right) .
\end{gathered}
$$

In the equivalent circuit and the transfer matrix the quantity $Z_{h}$ appears. It is defined by:

$$
Z_{h}=Z_{s}-Z_{a} / 4
$$

The lengths included in the above expressions are given hereafter. tonehole height. It

$$
Z_{a}=j k Z_{c} t_{a}
$$




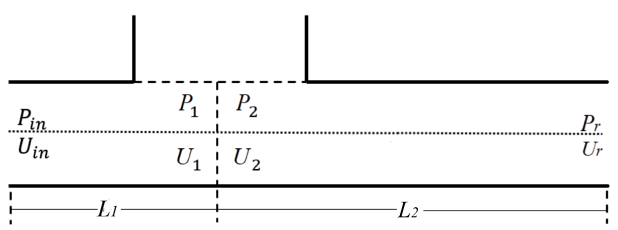

FIG. 1. Scheme of the tonehole geometry and acoustic variables.

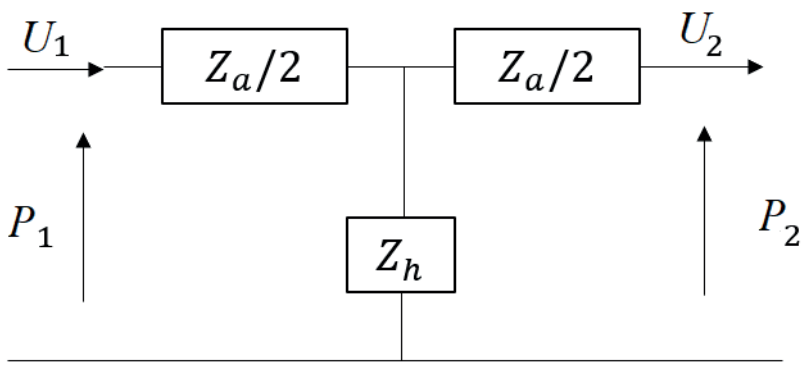

FIG. 2. Equivalent circuit for the tonehole

$$
Z_{s}=j Z_{c h}\left(k t_{i}+\tan \left[k_{b} t+k\left(t_{m}+t_{r}\right)\right]\right)
$$

88

In the equivalent circuit the quantity $Z_{h}$ is defined by:

$$
Z_{h}=Z_{s}-Z_{a} / 4
$$

89 The lengths included in the above expressions are given hereafter. If $\delta=b / a$, the series 90 length correction $t_{a}$ is given $\mathrm{by}^{3}$ :

$$
t_{a}=-b \delta^{2} /\left[1.78 \tanh (1.84 t / b)+0.94+0.540 \delta+0.285 \delta^{2}\right]
$$


This quantity is very small (a typical value is $0.5 \mathrm{~mm}$ ). For this reason several authors neglect the corresponding term in Eq. 6. However, in the matrix $M_{h}$ it is not consistent to ignore a quantity in one element while keeping it in the other elements. This remark can be related to the dual role of pressure and volume velocity in Eq. (3). At low frequencies, the length $t_{i}$, due to evanescent modes, is independent of frequency and can be regarded as an internal length correction for the tonehole height. It was written in Dubos et $\mathrm{al}^{3}$, and corrected by Dalmont ${ }^{7}$ :

$$
t_{i}=b\left(0.82-0.193 \delta-1.09 \delta^{2}+1.27 \delta^{3}-0.71 \delta^{4}\right)
$$

The length $t_{m}$ is related to the matching volume between the tonehole and the main tube, and cannot be exactly computed with the modal matching method, except when the main tube is rectangular (in which case it vanishes). Its value is given by ${ }^{4}$ :

$$
t_{m}=b \delta\left(1+0.207 \delta^{3}\right) / 8
$$

The length $t_{r}$ is the (complex) radiation length given by $t_{h}=Z_{r h} /\left(j k Z_{c h}\right)$, where $r$ is the subscript for the tube end, and $Z_{r h}$ the radiation impedance of the tonehole. Different expressions exist in the literature. For the sake of simplicity, we assume that it is equal to the radiation of a tube without flange ${ }^{12}$ ). At low frequencies, the order of magnitude of the uncertainty concerning the length correction is $0.2 b$, if losses near the walls are ignored, the total equivalent height of the tonehole is defined as:

$$
t_{s}=\operatorname{Im}\left(Z_{s} /\left(k Z_{c h}\right)\right) .
$$

At low frequencies, it is equal to:

$$
t_{s}=t_{i}+t+t_{m}+\operatorname{Re}\left(t_{r}\right) .
$$


The geometric values chosen in this paper are the tonehole radius $b=4 \mathrm{~mm}$ (the main tube radius is $a=7.3 \mathrm{~mm}$ ), and height $t=8.5 \mathrm{~mm}$; the matching length correction is $t_{m}=0.3$ $\mathrm{mm}$. The length correction for radiation is $t_{r}=2.5 \mathrm{~mm}$ (with a significant uncertainty of $0.2 b=0.8 \mathrm{~mm}$ ) and the internal length correction is $t_{i}=2.1 \mathrm{~mm}$. The total equivalent height is therefore $t_{s}=13.4 \mathrm{~mm}$. This quantity is of major interest for the computation of the input impedance of an instrument. Using the standard transmission line theory, a difference can be computed: it is of $1 \mathrm{~mm}$, and implies a typical shift of the first impedance peak of a clarinet-like instrument by $0.5 \%$ to $1 \%$ (i.e., 9 to 17 cents). Therefore the cumulative shift for several toneholes can be rather high.

\section{TUBE REVERSED METHOD}

\section{A. From the radiation impedance of the main tube to its input impedance}

For the present method, the main tube is open and the tonehole is not located at the middle of the tube, in order to obtain two different input impedances when the tube is reversed. The two different situations are $L_{1}<L_{2}$, and $L_{1}^{\prime}<L_{2}^{\prime}$, when in the second case the tube is reversed such that $L_{1}^{\prime}=L_{2}$, and $L_{2}^{\prime}=L_{1}$. The apostrophe indicates the reverse situation. $M_{1}$ and $M_{2}$ are the transfer matrices of the cylindrical sections of the tube $(i=1,2)$ :

$$
M_{i}=\left(\begin{array}{cc}
A_{i} & B_{i} \\
C_{i} & A_{i}
\end{array}\right)=\left(\begin{array}{cc}
\cos k_{a} L_{i} & j Z_{c} \sin k_{a} L_{i} \\
j Z_{c}^{-1} \sin k_{a} L_{i} & \cos k_{a} L_{i}
\end{array}\right) .
$$


Finally the input impedance is derived from (in is the subscript of the tube input):

$$
\left(\begin{array}{c}
P_{i n} \\
U_{i n}
\end{array}\right)=M_{1} M_{h} M_{2}\left(\begin{array}{c}
P_{r} \\
U_{r}
\end{array}\right) .
$$

The radiation impedance $Z_{r}$ is projected back to the right of the tonehole, as follows:

$$
Z_{2}=\frac{A_{2} Z_{r}+B_{2}}{C_{2} Z_{r}+A_{2}}
$$

Similarly, the impedance $Z_{1}$ at the left of the tonehole and the input impedance $Z_{\text {in }}$ are calculated by using the projection formula.

\section{B. Inverse problem}

The input impedance $Z_{i n}$, assumed to be known, is projected to the left of the tonehole, multiplying by the inverse matrix of $M_{1}$ as:

$$
\left(\begin{array}{c}
P_{1} \\
U_{1}
\end{array}\right)=\left(\begin{array}{cc}
A_{1} & -B_{1} \\
-C_{1} & A_{1}
\end{array}\right)\left(\begin{array}{c}
P_{i n} \\
U_{\text {in }}
\end{array}\right)
$$

$$
\Rightarrow Z_{1}=\frac{A_{1} Z_{\text {in }}-B_{1}}{-C_{1} Z_{\text {in }}+A_{1}}
$$

Following Fig. 2, the equations for the 3 elements of the electrical equivalent circuit can be written: Defining $P=Z_{h}\left(U_{1}-U_{2}\right) ; P_{1}=Z_{1} U_{1}=P+Z_{a} / 2 U_{1} ;$ and $P_{2}=Z_{2} U_{2}=P-Z_{a} / 2 U_{2}$, the following equation is obtained:

$$
\frac{1}{Z_{h}}=\frac{1}{Z_{1}-Z_{a} / 2}-\frac{1}{Z_{2}+Z_{a} / 2} .
$$


A similar equation holds for the second situation (reversed tube), replacing $Z_{1}$ and $Z_{2}$ by $Z_{1}^{\prime}$ and $Z_{2}^{\prime}$, respectively.

$$
\frac{1}{Z_{h}}=\frac{1}{Z_{1}^{\prime}-Z_{a} / 2}-\frac{1}{Z_{2}^{\prime}+Z_{a} / 2} .
$$

The following quadratic equation is obtained by eliminating $Z_{h}$ :

$$
A Z_{a}^{2} / 4+B Z_{a} / 2+C=0,
$$

$$
\begin{gathered}
A=\left(Z_{1}^{\prime}-Z_{1}\right)-\left(Z_{2}^{\prime}-Z_{2}\right) ; \\
B=2\left(Z_{1}^{\prime} Z_{2}^{\prime}-Z_{1} Z_{2}\right) ; \\
C=Z_{2}^{\prime} Z_{2}\left(Z_{1}^{\prime}-Z_{1}\right)-Z_{1}^{\prime} Z_{1}\left(Z_{2}^{\prime}-Z_{2}\right)
\end{gathered}
$$

Eq. (22) can be solved for $Z_{a}$, then $Z_{h}$ is derived from Eq. (20) or Eq. (21). However a simpler solution is obtained by expressing $Z_{h}$ with respect to $Z_{a}$. Using Eqs. (20 and 22) and eliminating $Z_{a}^{2}$, it can be written as:

$$
Z_{h}=-\frac{B}{2 A}-\frac{Z_{a}}{2} .
$$

Then, introducing this result in the quadratic equation (22), the following result is obtained:

$$
Z_{h}^{2}=\frac{B^{2}}{4 A^{2}}-\frac{C}{A}
$$

Two solutions exist for this equation. The solution with a negative real part can be eliminated because the physical system is passive. $Z_{s}$ can be deduced from Eq. (6):

$$
Z_{s}=Z_{h}+Z_{a} / 4 .
$$


FIG. 3. (Color online) Equivalent height $t_{s}$ of the tonehole (in $\mathrm{m}$ ). Solid, red line: model; blue, dotted line: inverse problem (from Eq. (25)). Dimensions $a=7.3 \mathrm{~mm}, b=4 \mathrm{~mm}, t=8.5 \mathrm{~mm}$, $L_{1}=44 \mathrm{~mm}, L_{2}=74 \mathrm{~mm}$.

155

156 of the tonehole $t_{s}$, given by Eqs. $(13,25,26)$; the real part of $Z_{h}$ and the imaginary part of $Z_{a}$, from Eq. (24). The results of the inverse problem were checked by using computed input impedances, and the order of magnitude of the numerical error is smaller than $10^{-14}$. Fig. 3 shows the comparison between the direct and the inverse computations for the equivalent height of the tonehole $t_{s}=\operatorname{Re}\left(Z_{s} /\left(j k S_{c h}\right)\right.$. For $Z_{a}$, the numerical error is smaller than $10^{-12}$. For other choices of termination impedance, such as an infinite impedance or the characteristic impedance, the entire computation remains valid. When the frequency tends

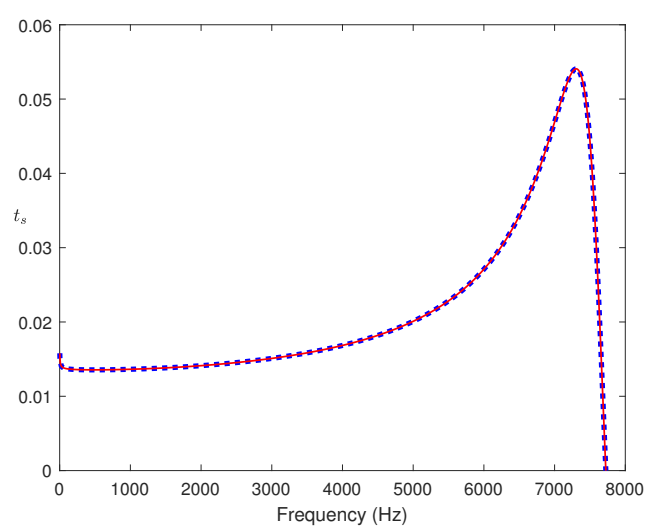

\section{(1)}

to zero, the small increase is due to the visco-thermal dispersion, which diminishes the sound speed, and increases the equivalent length. Furthermore, the strong variation at higher frequencies is due to the propagation of the planar mode in the tonehole (see the

Throughout this paper, the results are focussed on 3 quantities: the total equivalent height 
function $\tan (\mathrm{x})$ in Eq. (6)). The resonance near $7540 \mathrm{~Hz}$ corresponds to the minimum of the input impedance of the tonehole.

\section{Numerical simulation of the experiment: effect of uncertainty on the main tube length}

In order to simulate the experiment, errors are introduced on the data of the inverse problem. The input impedance is first computed, and the values are treated as experimental data. We start with an error of $0.2 \mathrm{~mm}$ on the length $L_{1}$. For the second case, an error of $0.2 \mathrm{~mm}$ on the length $L_{1}$ is considered together with an opposite error on the length $L_{2}$ (the later case corresponds to an error on the location of the tonehole, without change in the total length $L_{1}+L_{2}$ ). For the equivalent height of the hole $t_{s}$, Fig. 4 shows the comparison between results for the two cases simulated and the theoretical result (without errors introduced). Between $1550 \mathrm{~Hz}$ and $1650 \mathrm{~Hz}$, the error on the result is very large. Because this also happens at other higher frequencies, the figure is limited to $2000 \mathrm{~Hz}$. The frequency ranges with large error are close to the input impedance minima of the main tube ( $1560 \mathrm{~Hz}$ for $Z_{\text {in }}$ and $1610 \mathrm{~Hz}$ for $Z_{i n}^{\prime}$ ). A simple qualitative interpretation is the following: suppose that the radiation impedance of the tube is 0 (whatever the frequency), and that the input impedance vanishes at a given frequency, therefore the eigenfrequencies of the tube in the two positions are equal, and the problem becomes ill-posed (one equation for two unknowns): the solutions tend to infinity. This reasoning is not exact, because the radiation impedance is small, but not 0 . The variations of $t_{s}$ are very small up to 1400 $\mathrm{Hz}$, as well as the discrepancies with the theoretical values. Concerning the real part of the 
JASA/ Tube reversed method

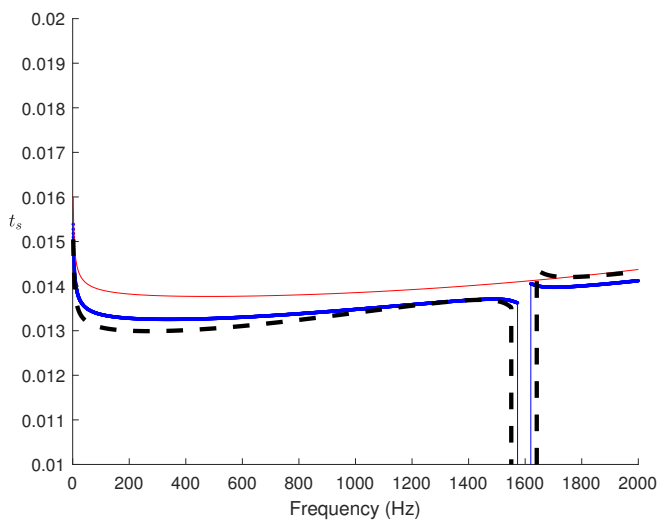

FIG. 4. (Color online) Equivalent height $t_{s}$ (in $\mathrm{m}$ ). Red, solid thin line: theory without length errors. Blue, thick, solid line: inverse problem (Eq. (25) with $0.2 \mathrm{~mm}$ error on $L_{1}$. Black, dashed line: inverse problem with $0.2 \mathrm{~mm}$ error on $L_{1}$ and $-0.2 \mathrm{~mm}$ error on $L_{2}$. satisfactory up to $1400 \mathrm{~Hz}$.

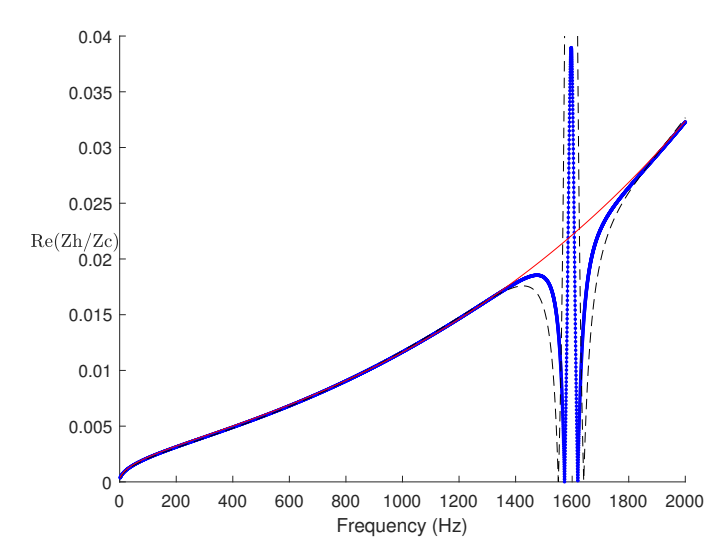

FIG. 5. (Color online) Real part of the shunt impedance $Z_{h}$. See line definitions in the caption of Fig. 4.

187

shunt impedance $Z_{h}$, it can be seen in Fig. 5 that the accuracy of the simulated results is

However, concerning the imaginary part of the series impedance $Z_{a}$, even a very small error on the lengths causes large errors on the result (see Fig. 6). Even the sign of the 
JASA/ Tube reversed method

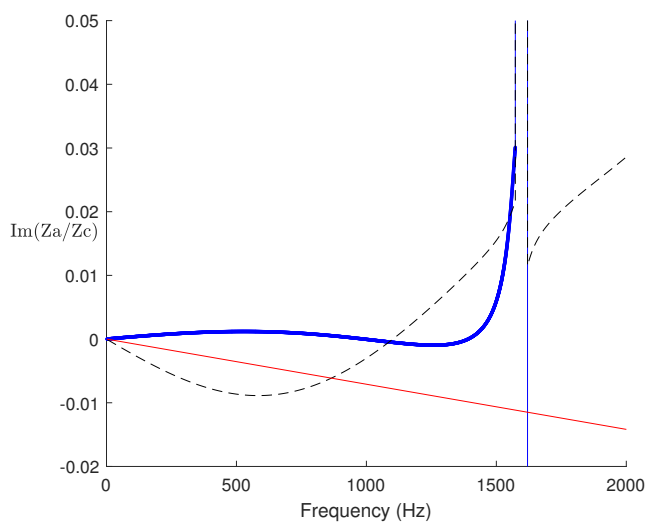

FIG. 6. (Color online) Imaginary part of the series impedance $Z_{a}$. See line definitions in the caption of Fig. 4.

quantity is not determined. This result suggests that it is extremely difficult to expect a precise measurement of the series impedance. From this perspective, the method is less robust than the method of the input and transfer impedance ${ }^{7}$, even if the later is not very precise (the uncertainty is almost 35\%). The present method is probably not suitable for measuring this element through experimentation.

\section{Numerical simulation of the experiment: effect of the uncertainty on the mea-} sured input impedance

A second attempt to simulate the experiment is based on the introduction of a random error on the input impedance (for the two configurations of the main tube $Z_{\text {in }}$ and $Z_{\text {in }}^{\prime}$ ). The input impedance is modified as follows:

$$
\widetilde{Z_{i n}}=Z_{i n}\{1+0.005[\operatorname{rand}(N)-0.5]\}
$$


The number $\mathrm{N}$ is the size of the input impedance vector. rand is a Matlab function that generates uniform pseudo-random numbers in the interval $[0,1]$. The value 0.005 is determined by the measurement of many input impedances. It means that the error modelled ranges from $-0.25 \%$ to $0.25 \%$ of $Z_{i n}$. The three figures 7 to 9 show a confirmation of the previous observations: the measurement can be accurate up to $1400 \mathrm{~Hz}$ for the shunt impedance, but the measurement of the series impedance is not possible (see Figs. 7 to 9).

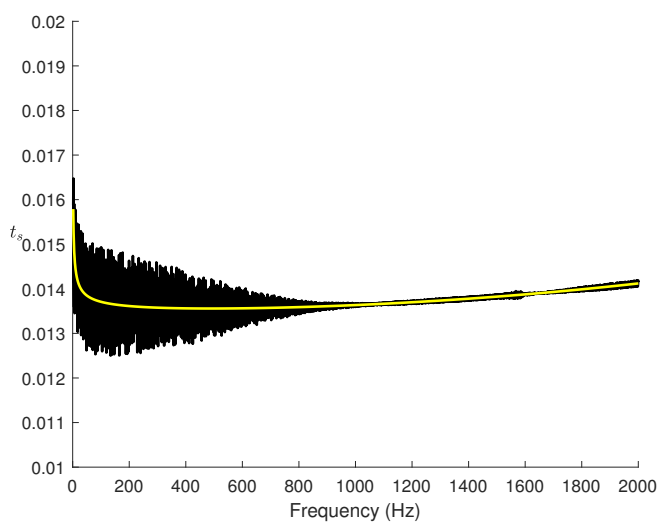

FIG. 7. (Color online) Tonehole equivalent height $t_{s}$ (in $\mathrm{m}$ ). Black lines: result of a simulation with a random error on the input impedance of the tube (Eq. (27)). Yellow line: no random error.

E. Practical considerations for the dimensions of the main tube

A conclusion of the simulation study implies that the main tube has to be chosen to be as short as possible. In order to avoid the coupling of evanescent modes between the tonehole and the radiating termination, the distance $L_{1}$ between the tonehole and the termination can be chosen between 2 and 3 times the main tube diameter. Furthermore the value of the first minimum frequency implies a small total length $L_{1}+L_{2}$. However it is essential that 
JASA/ Tube reversed method

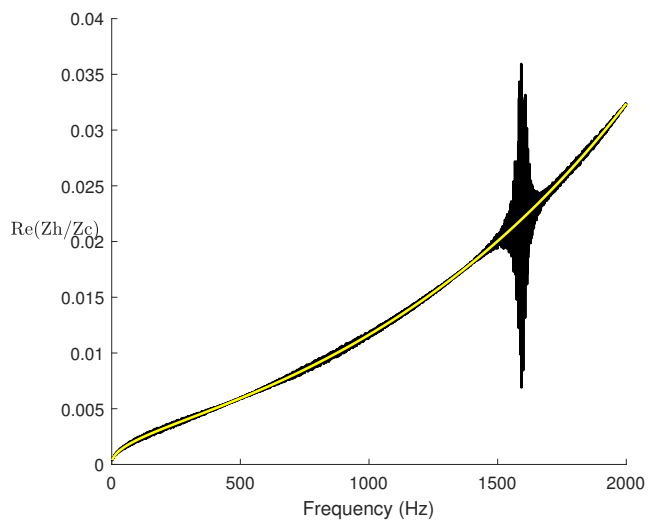

FIG. 8. (Color online) Real part of the shunt impedance $Z_{h}$. Black lines: result of a simulation with a random error on the input impedance of the tube (Eq. (27). Yellow line: no random error.

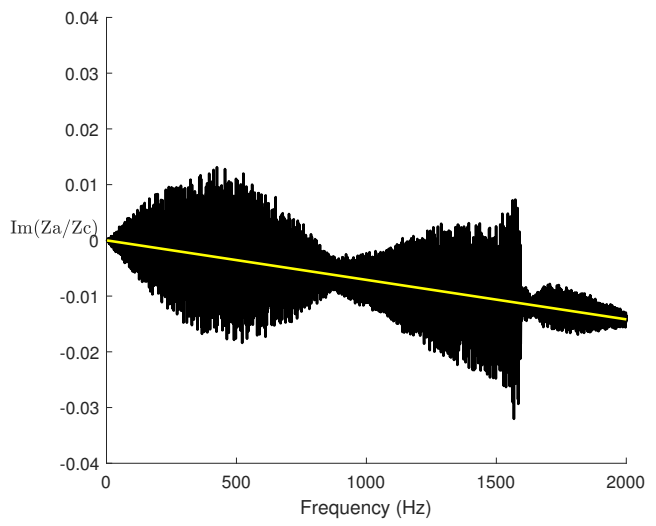

FIG. 9. (Color online) Imaginary part of the series impedance $Z_{a}$. Black lines: result of a simulation with a random error on the input impedance of the tube (Eq. (27). Yellow line: no random error. degenerate. The convenient choice for the $L_{2}$ is between 2 and 3 times the length $L_{1}$. 


\section{EXPERIMENTAL RESULTS FOR CYLINDRICAL TONEHOLES}

\section{A. Input impedance measurement}

The previous analysis encourages us to study an experiment based upon the method presented in the present paper. The method is tested experimentally by using wood pieces, and the CTTM sensor ${ }^{13}$ for the impedance measurement. A piezoelectric buzzer is used as a source. The pressure in the back cavity of the buzzer is measured by a microphone, which gives an estimation of the volume velocity. The measured pipe is connected to the front of the buzzer via a small open cavity in which a second microphone measures the pressure. The input impedance of the pipe is at first order proportional to the transfer function between the two microphones. The comparison with theoretical results for cylindrical tubes (without toneholes) is satisfactory: the discrepancy for a closed tube is 4 cents for the resonance frequencies and $1 \mathrm{~dB}$ for the peak heights, except at very low frequencies. For this reason, measurements are done above $200 \mathrm{~Hz}$.

\section{B. Preliminary results concerning the repeatability of the measurement}

We first study the repeatability for a tube and a tonehole with dimensions equal to those previously considered. For the frequency range 200 to $1400 \mathrm{~Hz}$, the equivalent height $t_{s}$ of the tonehole is found to be between $14.4 \mathrm{~mm}$ and $15.5 \mathrm{~mm}$, while the theoretical value (from Eq. (13) is $13.4 \mathrm{~mm}$. For 4 measurements after disassembly and assembly, the uncertainty is found to be about 1 to $2 \%$ (see Fig. 10). Furthermore Fig. 11 shows the comparison between the measurements of 4 tubes built with the same tools. The results are distributed on both 
sides of the theoretical one. This is an effect of the manufacturing tolerance, which is of the same order of magnitude as the measurement uncertainty, or higher. For all experimental results, the Matlab function smooth has been used. We remark measurements are not necessarily taken on the same day and at the same temperature, but the computation took it into account.

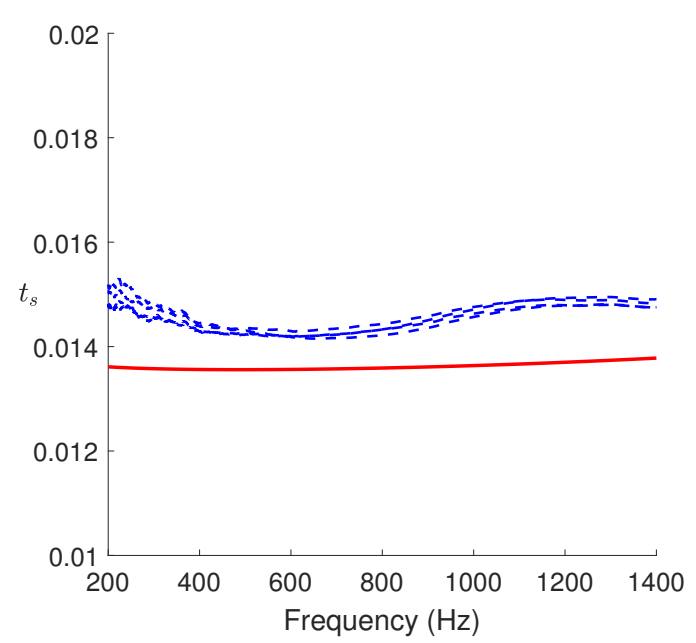

FIG. 10. (Color online) Tonehole equivalent height measured 4 times after disassembly. Blue, dashed lines: measurements. Red, solid line: theory. Dimensions $a=7.3 \mathrm{~mm}, b=4 \mathrm{~mm}, t=8.5$ $\mathrm{mm}, L_{1}=44 \mathrm{~mm}, L_{2}=74 \mathrm{~mm}$.

Two tubes of total length $L_{1}+L_{2}=118 \mathrm{~mm}$ and $162 \mathrm{~mm}$ are compared. The tonehole is located at the same distance of one of the ends of the two tubes (44 $\mathrm{mm}$ ). This value is chosen to be 2.7 times the hole diameter. The dimensions of the hole are identical for the two tube lengths $(b=4 \mathrm{~mm} ; t=8.5 \mathrm{~mm})$. As expected, Fig. 12 shows a small inceease 
JASA/ Tube reversed method

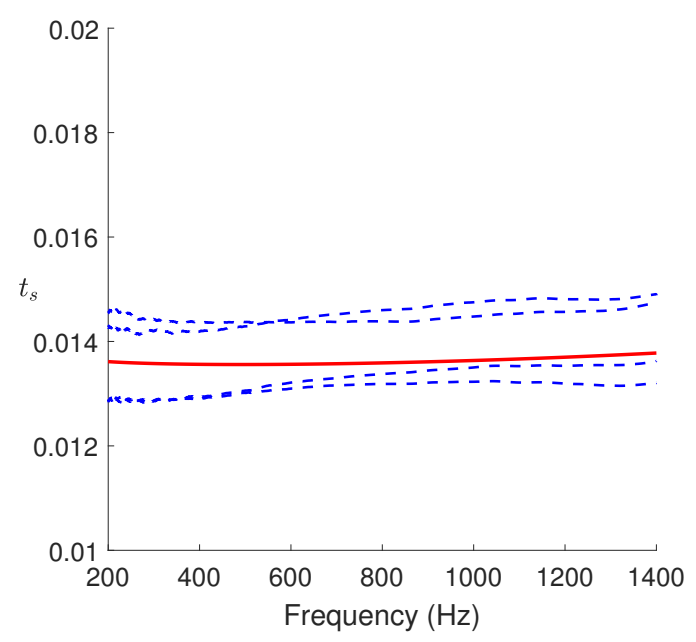

FIG. 11. (Color online) Tonehole equivalent height $t_{s}$ for 4 tubes built with the same tool. Blue, dashed lines: measurements. Red, solid line: theory.

when the frequency approaches the eigenfrequency of the tubes. As explained above, the short tube yields better results on a wider frequency range and the results are closer to the theoretical value, in particular near the measured minimum. The discrepancy between the results of the two tubes is about $3 \%$, except near the eigenfrequency. Concerning the real part of the shunt impedance, it appears that the two tubes yield very similar values, except in the vicinity of the eigenfrequency. Fig. 13 shows that they are higher than the theoretical values. Remember that for a linear functioning, radiation losses are proportional to $\omega^{2}$, while visco-thermal losses increase as $\sqrt{\omega}$. We refer to ${ }^{7}$ for a discussion about the theoretical aspects. Finally, the experiment confirms that the series impedance cannot be measured by the tube reversed method, as shown in Fig. 14 . 
JASA/ Tube reversed method

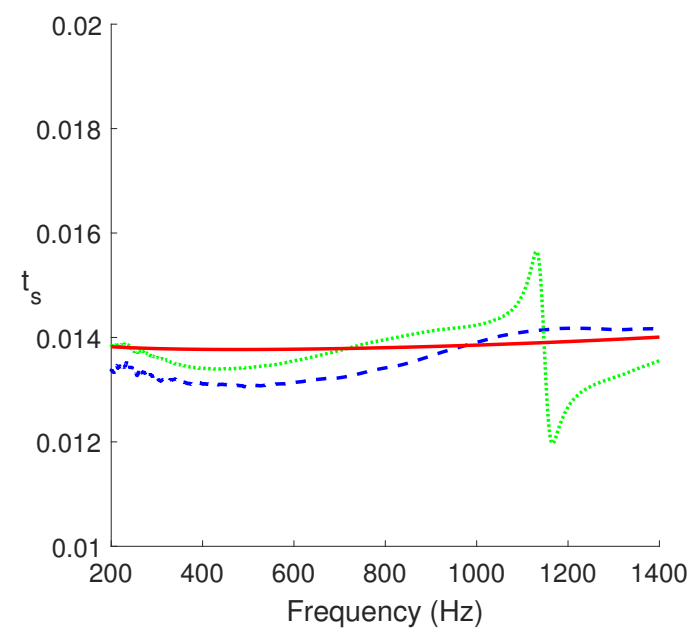

FIG. 12. (Color online) Measured value of the equivalent height $t_{s}$ of the hole. Green, dashed lines: long tube. Blue, dottted line: short tube. Red, solid line: theory

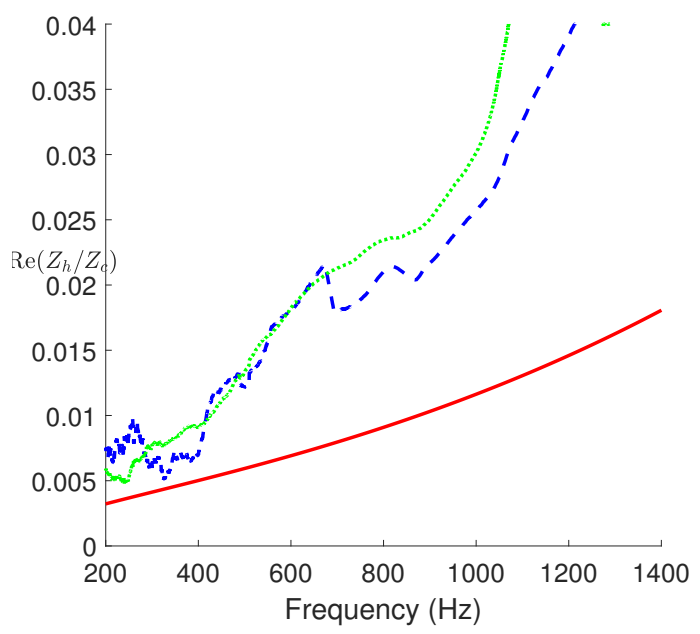

FIG. 13. (Color online) Measured value of the real part of the shunt impedance $\operatorname{Re}\left(Z_{h}\right)$ See the line definitions in the caption of Fig. 12. 
JASA/ Tube reversed method

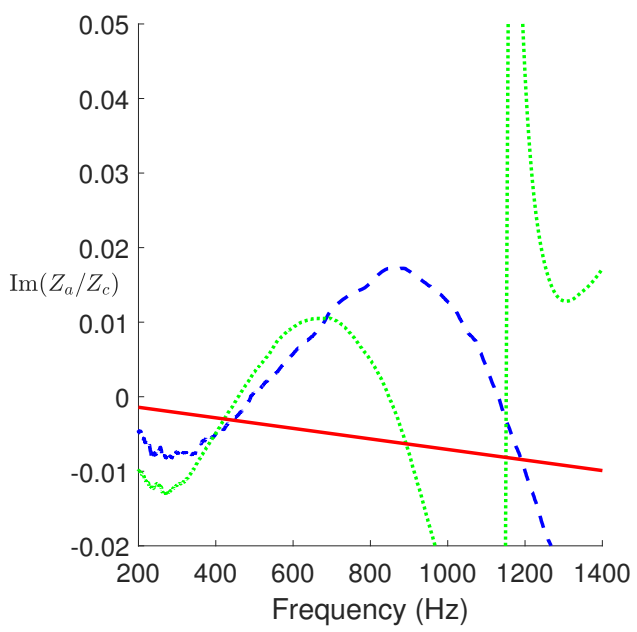

FIG. 14. (Color online) Measured value of the imaginary part of the series impedance $\operatorname{Im}\left(Z_{a}\right)$. See the line definitions in the caption of Fig. 12.

\section{EXPERIMENTAL RESULTS FOR UNDERCUT TONEHOLES}

Undercutting toneholes was studied for high excitation level bt Dalmont et $\mathrm{al}^{7}$ and Mcdonald $^{14}$ (see also ${ }^{15}$ ) for rectangular geometry. Nine short tubes of length $118 \mathrm{~mm}$ are holes drilled at $L_{1}=44 \mathrm{~mm}$ that have three different geometries: three are straight (but the hole is deburred), three are undercut by $2 \mathrm{~mm}$ and two are undercut by $3 \mathrm{~mm}$. Figs. 15 and 16 show the effect of undercutting the toneholes. The quantity shown by Fig. 15 is slightly different from that shown previously (see e.g. Fig. 13), because considering the length correction in Eq. (13) implies a division by the cross-section area $S_{h}$, but for the case of undercut toneholes, the area is not constant. For this reason, we choose the acoustic mass (per unit density) $m_{s}$ :

$$
m_{s}=Z_{h} /(j \omega \rho)
$$


The figures represent the average quantities for each geometry. The effect of undercutting is a decrease of $10 \mathrm{~m}^{-1}$ to $20 \mathrm{~m}^{-1}$ for the acoustic mass when the undercutting becomes wider. The jump below $400 \mathrm{~Hz}$ in Fig. 13 remains unexplained. Two causes for this mass increase can be analyzed. The widening implies a decrease of the acoustic mass of the plane mode, and also of the internal length correction due to the discontinuity between the main tube and the tonehole. The first of these causes can be modelled. Considering the acoustic mass for the cylindrical tonehole case, the result seems to be close to the theoretical result between $400 \mathrm{~Hz}$ and $600 \mathrm{~Hz}$. Calculating the average value, we obtain $280 \mathrm{~m}^{-1}$. For the cases of undercutting, we obtain $270 \mathrm{~m}^{-1}$ and $264 \mathrm{~m}^{-1}$.

An elementary model can be made in order to interpret these results. The shape of the most undercut tonehole is close to a cylinder extended in a truncated cone joining the internal wall of the main tube. For the cases studied, the lengths $\ell$ of the cylinder and $\ell^{\prime}$ of the cone are approximately equal to $\ell=\ell^{\prime}=5.5 \mathrm{~mm}$. The radius of the cylinder is $b=4 \mathrm{~mm}$, the small radius of the cone is $R_{1}=b$ and its large radius is $R_{2}=5.4 \mathrm{~mm}$. The calculation of the mass of a tube with variable cross section is done by integrating the inverse of the area along the axis. For a cone, the result is published in ${ }^{10}, \mathrm{p} .325$. It is that of a cylinder with a cross section equal to the geometric average of the radius: $S=\pi R_{1} R_{2}$. The difference between the cylindrical tonehole and the undercutting one is:

$$
\delta_{m}=\frac{\ell^{\prime}}{\pi b^{2}}\left[\frac{b}{R_{2}}-1\right]
$$

The result of this formula is $26 \mathrm{~m}^{-1}$. This result, based on approximate geometric and acoustic models, is consistent with the experimental data. This is encouraging for the use of an accurate measurement method for the computation of the input impedance of 
an instrument with undercut holes or other deviations from the cylindrical shape, such as holes with keypads. Furthermore, Fig. 16 shows that the effect of undercutting on the real part of the shunt impedance is small, but significant: it causes a decrease in resistance by approximately $10 \%$ as the undercut is increased from 0 to 2 and $3 \mathrm{~mm}$. . It is difficult to interpret the differences between the three geometries and their variation with frequency, and the influence of nonlinear effects cannot be ignored. However, a linear reasoning can be applied here: undercutting a tonehole broadens the effective radius, and visco-thermal effects diminish.

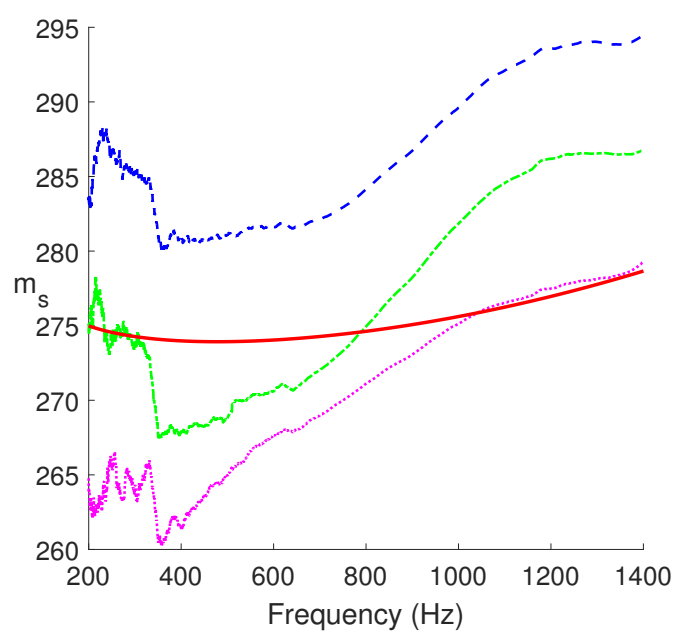

FIG. 15. (Color online) Measured value of the acoustic mass per unit density $m_{s}$ of the hole. Red, solid line: theory of a cylindrical tonehole in $m^{-1}$. From top to bottom, 3 geometries of the tonehole: Blue, dashed line: no undercutting; Green, dash-dot line: undercutting by $2 \mathrm{~mm}$; Magenta, dotted line: undercutting by $3 \mathrm{~mm}$ 


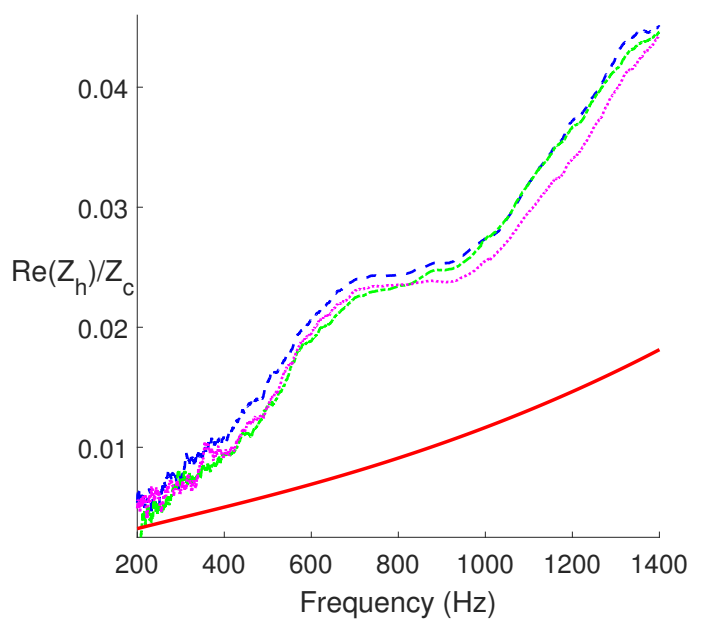

FIG. 16. (Color online) Measured value of the real part of the shunt impedance $\operatorname{Re}\left(Z_{h}\right)$. Red line: theory of a cylindrical tonehole. See line definitions in the caption of Fig. 15.

\section{CONCLUSION}

The method presented in this paper allows an evaluation of the effect of the complex shunt impedance of an open tonehole. We recall that the aim is to insert the experimental value in the computation of the input impedance of an instrument. The effect of a hole modification on the input impedance of an instrument is significant: a difference of $1 \mathrm{~mm}$ for the equivalent height may imply a shift of the first impedance peak. The cumulative shift for several toneholes can be rather high (see e.g. an article on the clarinet tuning ${ }^{11}$ ). It is important to use a short tube for this method, due to antiresonances associated to the total tube length. We remark that a similar problem concerning the "forbidden" frequency ranges is encountered in other methods. Moreover the distance of the hole to the tube end needs to be short. Concerning the real part of the shunt impedance, the results appear to be robust, and suggest further studies on the theoretical aspects, even for cylindrical 
toneholes in the linear regime. Concerning the imaginary part of the shunt impedance, the primary quantity studied here, the results seem to be very sensitive to small geometric differences. The relative variation of the equivalent height with frequency is small, and the absolute variation remains small. For a cylindrical tonehole, at approximately $500 \mathrm{~Hz}$, the discrepancy between experiment and theory is very small for the equivalent height $(0.1 \mathrm{~mm})$, and is of the same order of magnitude as the result obtained by other method ${ }^{7}$. The paper is limited to the frequency range $[200 \mathrm{~Hz}, 1400 \mathrm{~Hz}]$ for the measurements. It is concluded that the variation with frequency is mainly due to the measurement method. Assuming that the true value of the tonehole equivalent height is independent of frequency, the choice of an average of the values between 400 and $600 \mathrm{~Hz}$ as appropriate can be extended to any hole geometry. This result of the different cases examined in the present work can be used for including the acoustic characteristic of undercut tonehole in a computation of input impedances of an instrument.

The method is not convenient for measuring the series impedance. Actually this quantity is very small, but for this quantity the methods proposed in previous publications seem to be better. Concerning undercut toneholes, which are generally not symmetrical, in certain cases it could be useful to search for a circuit with 3 unknowns ${ }^{3}$. The aim of the present paper is not to improve a model, but it is useful in that it highlights some of the complications inherent in existing open tonehole models. The main improvement to existing models could be done on the radiation impedance of a tonehole. 


\section{ACKNOWLEDGMENTS}

The authors gratefully thank the French Association Nationale de la Recherche et la Technologie for the PhD grant of Héctor Garcia Mayén(CONVENTION CIFRE N² 2017 1600), as well as the french Agence Nationale de la Recherche, through the joint laboratory "Liamfi" between the Laboratoire de Mécanique et d'Acoustique and Buffet Crampon (ANR LCV2-16-007-01). Furthermore the authors thank the Consejo Nacional de Ciencia y Tecnología Políticas de Privacidad Acceso (Conacyt) for the International Scholarship 707987. The authors thank Buffet Crampon company for designing and manufacturing the wood pieces used in this article. Erik Petersen provided a careful reading of the English of the paper and gave useful comments, and Fabrice Silva helped for the experiment: they deserve the thanks of the authors.

\section{REFERENCES}

${ }^{1}$ E. Petersen, T. Colinot, J. Kergomard, P. Guillemain, "On the tonehole lattice cutoff frequency of conical resonators: applications to the saxophone", Acta Acust. 413 (2020). DOI: https://doi.org/10.1051/aacus/2020012

${ }^{2}$ D.H. Keefe, "Theory on the single woodwind tone hole", J. Acoust. Soc. Am. 72(3), 676-687 (1982).

${ }^{3}$ V. Dubos, J. Kergomard, A. Khettabi, J.P. Dalmont, D.H. Keefe, C. Nederveen, C.“ Theory of sound propagation in a duct with a branched tube using modal decomposition", Acust. Acta Acust. 85, 153-169 (1998). 
${ }^{4}$ C.J. Nederveen, J.K.M. Janssen, R.R. Van Hassel, "Corrections for woodwind tone-hole calculations". Acustica, 85 957-966 (1998).

${ }^{5}$ P. A. Dickens, "Flute acoustics, Measurement, modelling and design", Ph. D. Thesis, University of South Wales (2007).

${ }^{6}$ A. Lefebvre, G. Scavone, "Characterization of woodwind instrument toneholes with the finite element method" J. Acoust. Soc. Am. 131, 3153-3163 (2012).

${ }^{7}$ J.P. Dalmont, C.J. Nederveen, V. Dubos, S. Ollivier, V. Méserette, E. te Sligte, " Experimental determination of the equivalent circuit of an open side hole: linear and non linear behaviour". Acta Acust. United Acust. 88, 567-575 (2002).

${ }^{8}$ D.H. Keefe, "Experiments on the single woodwind tone hole", The Journal of the Acoustical Society of America 72, 688 (1982); https://doi.org/10.1121/1.388249.

${ }^{9}$ J.P. Dalmont, "Acoustic measurement, part II: a new calibration method", J. Sound Vib., 243, 441-459 (2001).

${ }^{10}$ A. Chaigne, J. Kergomard, "Acoustics of musical instruments", Springer Verlag, New York (2016).

${ }^{11}$ V. Debut, J. Kergomard, F. Laloe, "Analysis and optimisation of the tuning of the tweflthes for a clarinet resonator". Applied Acoustics 66, 365-409 (2005).

${ }^{12}$ F. Silva, P. Guillemain, J. Kergomard, B. Mallaroni, A.N. Norris, "Approximation formulae of the acoustic radiation impedance of a cylindrical pipe", J. Sound Vib., 322, 255-263 (2009). 
JASA/ Tube reversed method

377

378

379

380

381

382

${ }^{13}$ A. Macaluso, J.P. Dalmont, "Trumpet with near-perfect harmonicity: Design and acoustic results", J. Acoust. Soc. Am. 129, 404 (2011); https://doi.org/10.1121/1.3518769

${ }^{14}$ R. MacDonald, "A Study of the Undercutting of Woodwind Toneholes Using Particle Image Velocimetry", PhD Thesis, University of Edinburgh (2009). http://www.acoustics.ed.ac.uk/wp-content/uploads/Theses/Macdonald_Robert_ _PhDThesis_UniversityOfEdinburgh_2009.pdf

${ }^{383}{ }^{15}$ M. Temiz, I. Lopez Arteaga, A. Hirschberg, "Nonlinear behavior in tone holes in musical 384 instruments: an experimetal study", Conference CFA/Vishno, Le Mans 1-6 (2016). 